\title{
What's Worth Knowing? Research and Instructional Impacts of Books on Working-Class Academics
}

\author{
Jim Vander Putten, Mercer University
}

\begin{abstract}
What are the research impacts and instructional impacts of books of essays on the perspectives of faculty from working-class backgrounds? To what extent are these books used in undergraduate or graduate courses? Previous research on the content of these edited volumes has been limited to manual constant comparative analyses that described book content. This study employed data analysis methods in the emerging field of altmetric sciences to investigate the impacts of books of personal essays about faculty from working-class backgrounds $(\mathrm{N}=11)$. Book-level and chapter-level analyses were conducted to measure research impact using the Altmetric Explorer online tool and instructional impact using the Open Syllabus Project Explorer online tool. Data analysis results on research impacts for books on working-class academics produced extremely low impact levels. Few books $(\mathrm{N}=4)$ generated patterns of attention and these patterns were limited in scope. Data analysis results on instructional impacts identified that each of the 11 books generated a Teaching Score, but all scores were minimal and indicated low impact levels. The results suggest that scholarship on faculty from workingclass social origins is not being widely included in undergraduate or graduate course syllabi. Further, a large proportion of the book-level scholarship in the subject area of 'faculty diversity' has been limited to the constructs of race and gender. Issues involving faculty social origins have been largely omitted from curricula in this area and raises the important question: What is worth knowing?
\end{abstract}

\section{Keywords}

Higher education, faculty, social class

Reporters at The Chronicle of Higher Education investigated the question 'What's the most influential book of the past 20 years?' (Chronicle of Higher Education, 2018) and noted:

'Each year, more than 15,000 academic books are published in North America. A scant few will reach beyond their core audience of disciplinary specialists. Fewer still will enter the public consciousness.' In the arts and humanities, as well as many subdisciplines in the social sciences, the published book is the standard unit of academic productivity (Huang \& Chang 2008; Nederhof, 2006).

Clark (1973) reviewed the literature in the sociology of higher education and analyzed salient areas of scholarly inquiry. He assessed the scholarship in the field as being comprised of four areas, and one area is 'the study of 'academic man,' or higher education as a profession.' Gumport's (2007) discussion of Clark's (1973) work established important additional societal and organizational contexts for the study of college and university faculty. A significant body 
of book-level research on the US professoriate in general has been published, including Wilson's (1942) analysis of structures of faculty appointments, Lazarsfeld and Thielens' (1958) study of faculty during the McCarthy era, Lipset and Ladd's (1979) exploration of faculty and politics in the 1960s, Finkelstein's (1984) discussion of faculty roles, Schuster and Finkelstein's (2006) investigation of patterns of faculty research, and Finkelstein, Conley, and Schuster's (2016) examination of the present and future of the academic profession.

Focusing more specifically on books on faculty from working-class social origins, most are in the form of edited volumes of personal essays on various subgroups and roles: white workingclass male faculty in the social sciences (Ryan \& Sackrey, 1995), a diverse group of workingclass women faculty in the humanities (Tokarczyk \& Fay, 1993), LGBTQ faculty (Oldfield \& Johnson, 2008), instructional roles (Shepard, McMillan, \& Tate, 1998; Rosen, 2013), and women faculty relationships with their parents (Welsch, 2005), among several others.

Personal narratives by poverty-class and working-class people can raise consciousness of class inequality and provide powerful insights into their lives and experiences (Pifer \& Riffe, 2018; Launius, 2019).

These books have all made valuable contributions to the knowledge about this aspect of faculty worklife, diversity, and the marginalizing experiences of being an academic from a workingclass background in profoundly middle-class work environments (Van Galen \& Dempsey, 2009). However, further intellectual reductions into narrower subpopulations of faculty from working-class backgrounds raises questions about the significance of the scope and nature of future contributions to knowledge in this area.

One purpose of this study was to empirically investigate research and instructional impacts to identify the influences of these volumes of edited books that address the intersection of faculty and working-class social origins. Another purpose was to assist scholars in the sociology of higher education to gain deeper insights into the structure and impact of scholarship on one aspect of the 'study of higher education as a profession.' Two research questions guided this study:

1. What are the levels and patterns of research impact for books on working-class academics?

2. To what extent are books on working-class academics used to achieve instructional impact in undergraduate or graduate courses?

\section{Theoretical Framework}

The theoretical framework for this study is grounded in the previous scholarship in two areas: a) Working-Class Academics, and b) Measures of Research Impacts.

\section{Working-Class Academics}

Faculty from working-class backgrounds possess ambivalent feelings about the reference group and social class to which they identify; on one hand, this upbringing exerts significant influence on how one views their world. On the other hand, significant social mobility to the middle-class professions and the effects of the current social class position provides another influence on this view (Lubrano, 2003). Sennett and Cobb (1972) identified these feelings as 
status incongruity, and defined it as 'the discontent as a result of upward mobility from the social class of one's origin to a higher social class.' This incongruity creates discontent for poverty-class and working-class faculty (Ryan \& Sackrey, 1984), and this significant social class movement creates feelings of being 'out of place' in a social class higher than that of one's origin (Dews \& Law, 1993).

Many personal essays in edited volumes include heart-wrenching anecdotes describing the 'hidden injuries of class' (Sennett \& Cobb, 1972) in the form of classism and other obstacles these working-class academics encountered as they attempted to enter the typically middleclass work environments of higher education. Other anecdotes focused on difficult transitions involved in the significant social mobility to the middle-class and its unfamiliar culture. Stricker (2011) completed manual content analysis of 94 personal essays from working-class academics in five edited volumes published between 1985 and 2006. Her analysis found that many faculty began their careers devoting little attention to social class, but eventually became more outspoken. She also identified four areas in which institutions should view faculty social origins as a useful measure of faculty diversity. Pifer and Riffe (2018) completed document analysis of 166 publications of working-class academics' experiences in higher education. This analysis included ten edited volumes of books on working-class academics and identified two primary dimensions of experiences: understandings of institutions of higher educations as workplaces, and efforts to gain acceptance in scholarly communities. However, the research methods in these two studies were limited to manual constant comparative analyses that described book content.

\section{Measures of Research Impacts}

The concept of research impact has metamorphosed over the past several decades and has been constrained by the limits of available bibliographic technology (e.g., Heckman \& Martin, 1968). Fifty years ago, bibliographic research on publication patterns in higher education were completed by labor intensive manual inspection of publication reference lists and compilations of journals, authors, and research topics. Garfield developed the Journal Impact Factor measure which was considered the gold standard for measuring research impact (Williams \& Padula, 2015).

Over the past several decades, terminology has shifted from 'bibliographic research' to 'impact factor' to 'research impact' to reflect contemporary technological advances in data science. Focusing on a general definition of research impact, the Australian Engagement and Impact Assessment has defined it as: 'the contribution that research makes to the economy, society, environment or culture, beyond the contribution to academic research. ${ }^{1}$ However, this broad definition does not accurately address the specific characteristics of scholarship in workingclass studies or on working-class academics. Reed (2017) identified ten different types of research impact (e.g., 'Understanding and Awareness,' 'Economy,' 'Environment'). More specifically applicable to the present study, the type of impact that most accurately addresses working-class studies in general and first-person academic essays by faculty from workingclass backgrounds in particular is impact on 'Culture.' Reed defined this specific type of research impact as effecting 'changes in the prevailing values, attitudes, beliefs, discourse and patterns of behaviour... [or] social groups or society that deliver benefits to the members of those groups or those they interact with.' Further, Reed (2017) provided an example of cultural impacts that is directly applicable to the study:

\footnotetext{
${ }^{1}$ https://www.arc.gov.au/policies-strategies/strategy/research-impact-principles-framework
} 
'... research on working class entertainment might lead to changes in attitudes towards historic entertainment venues that had been left to fall into disrepair, leading to them being valued more greatly by members of the public. This might then lead to other forms of impact, for example economic impacts based on restoring historic entertainment venues that bring in visitors and revenue to previously overlooked locations.'

Taylor (2019) assessed the related literature on book-level metrics and observed that 'altmetrics that can show books' cultural influence, as well as non-traditional scholarly impacts.' Further, he noted that 'The research makes clear that anyone who wants to understand 'big picture' impact for a book or monograph should use a variety of data, rather than citation counts ... alone.'

In the past, book-level metrics were logical when scholars found research by reading print publications. However, with advancements in data science, a book's connection to a specific publisher is less important than how scholars find it or use it. Further, analyzing assigned readings from books and book chapters in university syllabi can provide insights into the educational utility of books in ways that citation counts cannot.

Faculty are often expected to provide evidence of impact from research in their respective fields and beyond to earn promotion and tenure. Measuring research impact is now easier than ever, and data science companies such as Altmetric, PlumX, PLOS, Dimensions, and FigShare have developed complex and wide-ranging databases of multiple online resources to measure patterns of dissemination and research impact.

Within the structure of contemporary scholarly measures, 'altmetrics' is the approach used in this study and are metrics that are not citation-based, but rather, social media metrics. In the past several years, altmetric data science on research impact has expanded to the humanities and social sciences.

\section{Methods of Inquiry}

Three decision rules framed the data analyses: the study was limited to edited books (a) comprised entirely of first-person essays by college and university faculty, (b) that included a focus on poverty-class or working-class social origins, and (c) that focused on faculty in the US. Books were excluded from the study if they reported empirical research findings (e.g, Grimes \& Morris, 1997), or if the edited books included essays by graduate students, staff, or people who did not work in higher education, or if the edited books included essays that did not focus on social class backgrounds. As a result, Books such as Gutierrez y Muhs, Niemann, González, and Harris (2012); Niemann, Gutierrez y Muhs, and González (2020), Standlee (2018) and Zandy (1990) were excluded from the study because they did not meet decision rules.

\section{Data Sources and Evidence}

The dataset for this study was comprised of eleven volumes of personal essays by US faculty from poverty- and working-class backgrounds that were published between 1993-2016. (See Table 1 for volumes used in the analyses). In addition, I disaggregated the eleven edited volumes into the 203 individual chapters to investigate: (a) research impacts of specific essays 
with individualized demographics and life experiences, and (b) instructional impacts of shorter readings as required course assignments.

\section{Data Analysis}

First, I used the proprietary online tool Altmetric Explorer ('Altmetric Explorer,' n.d.a) in the first stage of data analysis to measure research impact. The rationale for using this tool is because of the widespread adoption of Altmetric Explorer by university libraries, research journals, and book publishers. The websites of these organizations include visualizations of research impact for each individual publication and are presented in the form of 'donuts' that display the amount of research impact and sources of attention among the fifteen social media and research sources monitored by Altmetric Explorer. More importantly, for the purposes of accurate data science research, these research impact data and donuts are continuously updated with the most current impact data.

The Altmetric Explorer tool generates an 'Attention Score' for a research output (e.g., book, chapter) that measures the amount of attention it has received in 15 different online sources, including blogs, Facebook, Twitter, and LinkedIn ('Altmetric Explorer,' n.d.b) since 2011. Book-level attention scores are calculated from the weighted attention to the book and its chapters (See Table 2 for Altmetric sources and weighting) and an individual book's score is not the sum of all the chapters' scores. Similarly, these analyses are not a comparison between books; the book is unit of analysis, not the list of books. I searched for each book and generated results on the patterns of attention (See Table 3 for book-level attention scoring). In addition, I searched for each chapter of each book to investigate patterns of attention.

Second, I used the free Open Syllabus Project ('Open Syllabus Project,' n.d.) Explorer online tool in the second stage of data analysis to measure instructional impact. This database contains more than nine million English language college course syllabi from 140 countries that were obtained from instructor donations and from the Internet Archive's Wayback machine. However, no individual syllabi in the Syllabus Explorer are publicly available. The Syllabus Explorer online tool calculates the number of times a book appears in syllabi (i.e., 'appearance counts') and also generates an instructional 'score' ranging from 1-100 which is a scale of ranked appearance counts in the context of all 1.7 million book titles in the database. For example, Strunk's (1999) The Elements of Style is the top ranked book with more than 15,500 appearances and a rank of 100.

Third, I used Google Scholar to generate another metric on these eleven books that provided insights into more traditional patterns of impact. This data collection was completed at one point in time (March 2021) to assure consistency of results across publications and minimize the potential effect of a time window on changing citation counts.

\section{Results}

\section{Research Impact}

Using an entire book as the unit of data analysis, results to answer research question \#1 indicated extremely low levels of research impact for the eleven books on working-class academics in this study. Only four books out of eleven received any attention in the fifteen data sources monitored in the Altmetric database: Dews and Law (1993); Hurst and Nenga (2016); 
Muzzatti and Samarco (2006), and Ryan and Sackrey (1984/1996) and this attention occurred between July 2015 - August 2020 (See Table 3 for Research Impact).

In contrast to the metric of 'research impact,' the established 'impact factor' metric is easy to interpret because higher numbers are better. However, with regard to research impact scores, impacts of individual books are not judgments on the books themselves, because individual readers will obtain individual levels of meaning from them. In addition, books can generate widely different research impact scores depending upon either broad or narrow audiences. The numbers are much less significant than the types of mentions that a book receives because this illustrates dissemination patterns and helps to answer the questions: Where are people talking about this book and why?

Many of the books in this study were published before the Altmetric database was created in 2012. As a result, the research impact of these publications did not benefit substantially from contemporary technology or communication methods to disseminate knowledge and awareness. This can only be a partial explanation, however, and the two exceptions to this timeline limitation were Dews and Law (1993) with an Altmetric score of 20 and both editions of Ryan and Sackrey (1984/1996) which combined for an Altmetric score of nine. One possible explanation for these two books is that some individual essays might have addressed particularly specific, meaningful, or broadly applicable perspectives on academic work or life experiences that appealed to readers. However, research impacts for all books in the study occurred in other ways as evidenced by subsequent published volumes of personal essays and resulting citation counts.

For more specific analyses, I disaggregated the eleven edited volumes into the 203 individual chapters to investigate research impacts of essays that either focused on understanding contemporary topics at the chapter level, or on specific lived experiences of faculty from working-class backgrounds. Similar to the finding of low levels of research impact for entire books, there was no evidence of research impacts or patterns of attention for any of the 203 individual book chapters. This absence of evidence confirms Taylor's (2019) finding that 'only $1.8 \%$ of book chapters receive attention online' and one possibility is that scholars reference a chapter in a book by sharing a link to the entire book, rather than a direct link to the chapter.

\section{Instructional Impact}

Results to answer research question \#2 indicate that each of the eleven books in the study registered an Overall Teaching Score in the Open Syllabus Project database ('Open Syllabus Project,' n.d.) for instructional impact in undergraduate or graduate courses. However, the scores were uniformly low and ranged from 2 to 1 on a scale from 0 to 100 (See Table 3 for Instructional Impact). These low results are surprising when considered in the context of special focus professional associations, their special interest groups on social class in education and on working-class faculty, and presentations at annual conferences that are convened to discuss these issues (e.g., the Working-Class Academics section in the Working-Class Studies Association). Additionally, many of these organizations and groups have social media accounts across several platforms that have the potential to facilitate conversations around these meaningful books.

\section{Google Scholar Citations}


I included Google Scholar citation data in the analyses to provide traditional descriptive context to the low levels of research and instructional impacts that were measured by more innovative methods. This citation evidence demonstrates that some of these books have had substantial scholarly impact since their publication dates for the narrower audience of other academics writing on similar topics, but this evidence does not meet the definition of research impact (See Table 3 for Google Scholar citation counts).

\section{Conclusions}

The primary purpose of this study was to investigate research and instructional impacts of eleven edited volumes of personal essays by faculty from working-class backgrounds and this study is significant for several reasons. First, this study employed data analysis methods in the emerging field of altmetric sciences to answer sophisticated research questions about research and instructional impacts of the previous scholarship on faculty from working-class backgrounds. Previous research on edited volumes of essays by faculty from working-class backgrounds has focused internally on the content of the books, rather than externally to investigate research and instructional impact, as was completed in this study.

Second, the study purpose was to empirically identify the books on working-class faculty that were the most influential. This study represents a shift from anecdote to evidence; workingclass academics can identify strongly with personal essays in these edited volumes that resonate with their lived experiences. By extension, an assumption can be made that similar impacts occur for a large number of other faculty from working-class backgrounds. But for the most part, this produced surprising and counterintuitive findings. Perhaps this topic is less important to scholars and practitioners who may be looking for course materials that are related to more practical problems and issues being faced on campus. One pressing contemporary issue in higher education involves institutional diversity, equity and inclusion (DEI) policies and programs to promote the representation and participation of a diverse array of faculty, including those of different genders, races and ethnicities, religions, abilities and disabilities, ages, cultures, and sexual orientations. The study also achieved the purpose of understanding the structure and impact of scholarship in the sociology of higher education, but provided substantial evidence that this subfield of knowledge has not been widely taught in humanities or social sciences courses. This could be explained by the rapid pace of knowledge generation and a short-term focus on more current issues related to college and university faculty (e.g., diversification and retention of the professoriate).

\section{Limitations}

There are several potential limitations to this study. First, this research design does not measure research impact of books that are digitally linked between institutional learning management systems and library reserve holdings. Further, promotional announcements from authors that publicize new books via email or social media are often linked to retail websites (e.g., Amazon) and exclude necessary information such as ISBN or DOI that is necessary to be included in the Altmetric database, and this also masks research impact.

Second, with regard to the limitations of citation counts, Kousha, Thelwall, and Rezaie (2011) concluded that citation counts in Google Scholar are one source to help evaluate research impact in academic disciplines that view the book as the scholarly gold standard. Some of the books included in this study have notable citation counts indicating scholarly impact. While 
citation counts are one common metric for research impact, however, on a macro level this approach incentivizes dubious citation practices including overuse of self-citation and scholars can employ strategic citations practices to artificially increase research impact (Baccini, De Nicolao, \& Petrovich, 2020). Further, detecting these strategic citation behaviors at the individual publication level is difficult. Another limitation of using citation counts reported by Google Scholar is that book-level citation analyses have a four-five year lag time because of the slow nature of subsequent books published (S. Konkiel, personal communication, February 27, 2020).

Third, Kousha and Thelwall (2016) observed that success in teaching scholarship can be measured by book mentions in course syllabi. However, this is based on the assumption that students complete the assigned readings (Sharma, Van Hoof, \& Pursel, 2013). In fact, the results of one study suggested that less than $30 \%$ of psychology students completed assigned readings from course textbooks. As a result, book or chapter mentions in syllabi may not always be an accurate proxy for instructional impact.

\section{Structure and Function of Knowledge}

Books serve a vital role in scholarly communications and present unique perspectives that cannot be found through the production of more narrowly-focused journal articles. Edited volumes of essays on faculty from working-class backgrounds falls squarely in the subject category of 'faculty diversity.' Sharlet (1999) described the race-class-gender view as a triumvirate and raised the question, 'Is there a more familiar mantra in fin de siècle academe?' Unfortunately, much of the literature on faculty diversity has narrowly conceptualized it to issues of race and gender (e.g., Trower \& Chait, 2002; Moody, 2012; antonio \& Muñiz, 2007; Evans \& Chun, 2007; Gappa, Austin, \& Trice, 2007; Maher \& Tetreault, 2007; O'Meara, Terosky, \& Neumann, 2009; AFT, 2010; Minor, 2014) and issues of social class origins from poverty-class to upper-class have received much less attention in the scholarly literature. More recently, Ingram (2021) identified social class as the 'forgotten dimension of diversity.'

Examining the sociology of higher education scholarship on the academic profession in this area more closely, Rhoades' (2007) discussion of the literature on faculty race, gender, and social class also primarily addressed issues related to race and gender. This included hiring patterns for faculty of color, feminist scholarship, and gender stratification in the professoriate. According to Rhoades (2007), 'the sociology of professions in academe would benefit from an exploration of the role of professionals in relationship to social stratification and institutional and social change' (p. 135). Scholars have addressed this recommendation, but as indicated by the study findings, very little of it is being discussed or being taught.

In one sense, the instructional impacts of these books is a curriculum issue and at the individual course level, instructors or academic departments decide what knowledge is worth knowing. Notably, some of the most contentious discussion of curriculum reform in the United States occurred in the 1980s related to debates about whether to require multiculturalism courses in the general education curriculum at Stanford (Pratt, 1992). The United States is a culturally plural nation and the disproportionally low representation of social class in the literature on college and university faculty suggests what does and doesn't count in terms of cultural capital in course syllabi.

Any book can be intentionally written for either a broad or narrow audience, and scholarly books are no different. This is important to note because the modest results on research and 
instructional impacts suggest that these books attracted narrow audiences and have neither been discussed in social media nor included in courses on broader related topical issues. As a result, one broad consequence of these results on research impact is the reduced levels of awareness of the concept of faculty social class origins, in general, and working-class academics, in particular. Graduate students from poverty-class and working-class backgrounds who aspire to the professoriate and current faculty will be less likely to understand that this is an established subfield of study in the sociology of higher education and represents a recognized avenue for future scholarship.

A narrower consequence of the results on instructional impact is the limited learning that will occur for undergraduate and graduate students from poverty-class and working-class backgrounds. Students are less likely to be exposed to this body of literature and will have fewer opportunities for introspection and personal insights that can result from reflecting on the specific lived experiences and worldviews of faculty in the essays. In addition, students from poverty-class and working-class backgrounds will be less likely to recognize that working-class academics are allies who can serve as role models in the classroom and as mentors in successfully navigating the typically middle-class environments of college campuses. Another perspective on this issue can be framed by the question 'How diverse is your reading list?' (El Kadi, 2019) and much of this discussion relates to Eurocentrism in required undergraduate coursework in the humanities (Bird \& Pitman, 2019).

Since the data analysis generated extremely low levels of research and instructional impacts, another possible explanation for these results focuses on generational differences between scholars and levels of comfort with social media and self-promotion. A second plausible explanation involves faculty or administrators who may make value judgments regarding this type of faculty work. The provocative title of Lemke, Peters, and Mazarakis' (2019) blog entry 'If you use social media then you are not working' captures the essence of this sentiment. Other researchers view self-promotion on social media as uncomfortable or 'humblebragging' (Khoo, 2016).

Scholarship has progressed beyond the limits of hardcopy book catalogs and traditional publishing models. Academic research has become widely available online to be located, disseminated, and discussed. Scholars conducting research on issues of faculty diversity will benefit from understanding existing patterns of dissemination and attention to their research in order to identify reasons for, and nature of, discussions in their topical areas. In this way, scholars can identify subsequent uses of their work and generate new knowledge and make important contributions to knowledge in the future.

\section{Author Bio}

Jim Vander Putten is an Associate Professor of Higher Education in the PhD program in Educational Leadership at Mercer University (GA). He co-founded the annual conferences of the Working-Class/Poverty-Class Academics (WCPCA) microcommunity with Dr. Barbara Peters in 1993. His research interests focus on the influences of faculty social origins on worklife and productivity, research quality and impact, and academic freedom in an age of antiintellectualism.

\section{Acknowledgement}

I would like to thank Ken Oldfield for his suggestions on a previous version of this article. 


\section{Bibliography}

AFT. (2010). Promoting racial and ethnic diversity in the faculty: What higher education Unions can do. Washington, D.C.: American Federation of Teachers.

Altmetric Explorer (n.d.a). Altmetric for researchers. https://www.altmetric.com/audience/researchers/

Altmetric Explorer (n.d.b). Sources of attention. https://www.altmetric.com/about-ourdata/our-sources/

Altmetric.com (n.d.c). How is the Altmetric attention score calculated? https://help.altmetric.com/support/solutions/articles/6000233311-how-is-the-altmetricattention-score-calculated-

Altmetric.com (n.d.d). How is the Altmetric Attention Score calculated for books? https://help.altmetric.com/support/solutions/articles/6000134387-how-is-the-altmetricattention-score-calculated-for-books-

antonio, a., \& Muñiz., M (2007). The Sociology of Diversity. In P. Gumport (Ed.), Sociology of Higher Education (pp. 266-294), Johns Hopkins University Press.

Baccini, A., De Nicolao, G., \& Petrovich, E. (2020, January 8). How bibliometrics incentivize self-citation. Social Science Space. https://www.socialsciencespace.com/2020/01/howbibliometrics-incentivize-self-citation/

Bachrach, P., \& Baratz, M. (1962). Two faces of power. The American Political Science Review, 56(4), 947-952. https://doi.org/10.2307/1952796

Bird, K. S., \& Pitman, L. (2020). How diverse is your reading list? Exploring issues of representation and decolonisation in the UK. Higher Education, 79(5), 903-920.

Chronicle of Higher Education. (2018, October 30). What's the most influential book of the past 20 years? https://www.chronicle.com/interactives/influential-books

Clark, B. (1973). Development of the sociology of higher education. Sociology of Education, $46,2-14$.

Dews, B., \& Law, C. (Eds.), (1993). This fine place so far from home: Voices of academics from the working class. Temple University Press.

El Kadi, T. (2019, March 22). How diverse is your reading list?(Probably not very...), LSE Citing Africa Project. https://blogs.1se.ac.uk/impactofsocialsciences/2019/03/22/howdiverse-is-your-reading-list-probably-not-very/

Evans, A., \& Chun, E. 2007. Are the walls really down? Behavioral and organizational barriers to faculty and staff diversity. ASHE Higher Education Report, Volume 33 Number 1. Jossey-Bass.

Finkelstein, M. (1984). The American academic profession: A synthesis of social science inquiry since World War II. Ohio State University Press.

Finkelstein, M., Conley, V., \& Schuster, J. (2016). The faculty factor: Reassessing the American academy in a turbulent era. Johns Hopkins University Press.

Gappa, J., Austin, A., \& Trice, A. (2007). Rethinking faculty work: Higher education's strategic imperative. Jossey-Bass.

Gumport, P. (2007). Sociology of higher education. Johns Hopkins University Press.

Heckman, D., \& Martin, W. (1968). Inventory of current research on higher education 1968. Carnegie Commission on the Future of Higher Education.

Huang, M. \& Chang, Y. (2008). Characteristics of research output in social sciences and humanities: from a research evaluation perspective. Journal of the American Society for Information Science and Technology, 59(11), 1819-1828.

https://doi.org/10.1002/asi.20885 
Hurst, A., \& Nenga, S. (2016). Working in class: Recognizing how social class shapes our academic work. Rowman \& Littlefield.

Ingram, P. (2021, (January-February). The Forgotten Dimension of Diversity. Harvard Business Review. https://hbr.org/2021/01/the-forgotten-dimension-of-diversity

Khoo, T. (2016, August 9). Let's talk about the humblebrag. The Research Whisperer. https://researchwhisperer.org/2016/08/09/lets-talk-about-the-humblebrag/

Kousha, K. \& Thelwall, M. (2016), An automatic method for assessing the teaching impact of books from online academic syllabi. Journal of the Association for Information Science and Technology, 67, 2993-3007. https://doi.org/10.1002/asi.23542

Kousha, K., Thelwall, M., \& Rezaie, S. (2011). Assessing the citation impact of books: The role of Google Books, Google Scholar, and Scopus. Journal of the American Society for Information Science and Technology, 62 (11), 2147-2164. https://doi.org/10.1002/asi.21608

Launius, C. (2019, September 16). Memoir as medium: Bridging the class divide. https://workingclassstudies.wordpress.com/2019/09/16/memoir-as-medium-bridgingthe-class-divide/

Lazarsfeld, P., \& Thielens, W. (1958). The academic mind: Social scientists in a time of crisis. Free Press.

Lemke, S., Peters, I., \& Mazarakis, A. (2019, March 20). 'If you use social media then you are not working' - How do social scientists perceive altmetrics and online forms of scholarly communication? https://blogs.lse.ac.uk/impactofsocialsciences/2019/03/20/if-you-usesocial-media-then-you-are-not-working-how-do-social-scientists-perceive-altmetricsand-online-forms-of-scholarly-communication/

Lipset, S., \& Ladd, E. (1979). The changing social origins of American academics. In R. Merton, J. Coleman, and P. Rossi (Eds.), Qualitative and quantitative social research (pp. 28-43). Free Press.

Lubrano, A. (2003). Limbo: Blue-collar roots, white-collar dreams. Wiley.

Maher, F., \& Tetreault, M. 2006. Privilege and diversity in the academy. Routledge.

Minor, J. (2014). Faculty diversity and the traditions of academic governance. New Directions for Institutional Research, 159, (pp. 49-61). https://doi.org/10.1002/ir.20053

Moody, J. (2012). Faculty diversity: Removing the barriers ( $\left.2^{\text {nd }} E d.\right)$. Routledge.

O'Meara, K., Terosky, A, \& Neumann, A. (2009). Faculty careers and work lives: A professional growth perspective. ASHE Higher Education Report, Volume 34, Number 3. Jossey-Bass.

Nederhof, A. (2006). Bibliometric monitoring of research performance in the social sciences and the humanities: A review. Scientometrics, 66(1), 81-100. https://doi.org/10.1007/s11192-006-0007-2

Oldfield, K., \& Johnson, R. (2008). Resilience: Queer professors from the working class. SUNY Press.

Open Syllabus Project database (n.d.). https://blog.opensyllabus.org/

Pifer, M., \& Riffe, K. (2018). Working-class academics at work: Perceptions of and experiences in the academy. In A. Standlee (Ed.), On the Borders of the Academy: Challenges and Strategies for First Generation Graduate Students and Faculty (pp. 6780). Syracuse University Press.

Pratt, M. (1992). Humanities for the future: Reflections on the western culture debate at Stanford (pp. 13-31). In D. Gless and B. Smith (Eds.), The politics of liberal education. Duke University Press.

Reed, M. (2017). What types of impact are there? Fast Track Impact. https://www.fasttrackimpact.com/what-types-of-impact-are-there-subp 
Rosen, R. (2013). Class and the college classroom: Essays on teaching. Bloomsbury Academic.

Ryan, J., \& Sackrey, C. (1995). Strangers in paradise. South End Press.

Schuster, J., Finkelstein, M. (2006). The American faculty: The restructuring of academic work and careers. Johns Hopkins University Press.

Sennett, R., \& Cobb, J. (1977). The hidden injuries of class. Norton.

Sharlet, J. (1999, July 23). Seeking solidarity in the culture of the working class. The Chronicle of Higher Education.

Sharma, A., Van Hoof, B., \& Pursel, B. (2013). An assessment of reading compliance decisions among undergraduate students. Journal of the Scholarship of Teaching and Learning, 13(4), 103-125.

Stricker, K. (2011). Class consciousness and critical mass; Exploring the practice and scholarship of academics from the working class. Race, Gender \& Class, 18(3-4).

Shepard, A., McMillan, T., \& Tate, G. (1998). Coming to class: Pedagogy and the social class of teachers. Boynton/Cook.

Standlee, A. R. (2018). On the borders of the academy: Challenges and strategies for firstgeneration graduate students and faculty. Syracuse University Press.

Strunk, W., \& White, E. (1999). The elements of style (4th edition). Allyn-Bacon.

Taylor, M. (2019, October 17). 'Altmetric For Books: 3 Years Out, What Have We Learned?,' Altmetric Blog. https://www.altmetric.com/blog/altmetric-for-books-3-years-out-whathave-we-learned/

Tokarczyk, M., Fay, E. (1993). Working-class women in the academy: Laborers in the knowledge factory. University of Massachusetts Press.

Trower, C., \& Chait, R. (2002). Faculty diversity: Too little for too long. Harvard Magazine, 104(4), 33-38. https://www.harvardmagazine.com/sites/default/files/pdf/2002/03pdfs/0302-33.pdf

Van Galen, J., \& Dempsey, V. (2009). Trajectories: The educational and social mobility of education scholars from poor and working-class backgrounds. Sense.

Welsch, K. (2005). Those winter Sundays: Female academics and their working-class parents. University Press of America.

Williams, C., \& Padula, D. (2015). The evolution of impact indicators: From bibliometrics to altmetrics. Scholastica. https://scholasticahq.com/altmetrics-the-evolution-of-impactindicators

Wilson, L. (1942). The academic man: A study in the sociology of a profession. Oxford University Press.

Rhoades, G. 2007. The study of the academic profession. In Patricia Gumport (Ed.) Sociology of higher education (p. 113-146). Johns Hopkins University Press.

Zandy, J. (1990). Calling home: Working class women's writings. Rutgers University Press. 


\section{Table 1}

Books Included in the Analyses

Adair, V., \& Dahlberg, S. (2003). Reclaiming class: Women, poverty, and the promise of higher education in America. Temple University Press.

Dews, B., \& Law, C. (Eds.), (1993). This fine place so far from home: Voices of academics from the working class. Temple University Press.

Hurst, A., \& Nenga, S. (2016). Working in class: Recognizing how social class shapes our academic work. Rowman \& Littlefield.

Muzzatti, S., \& Samarco, C. (2006). Reflections from the wrong side of the tracks: Class, identity, and the working class experience in academe. Rowman \& Littlefield.

Oldfield, K., \& Johnson, R. (2008). Resilience: Queer professors from the working class. SUNY Press.

Rosen, R. (2013). Class and the college classroom: Essays on teaching. Bloomsbury Academic.

Ryan, J., \& Sackrey, C. (1984/1995). Strangers in paradise. South End Press.

Shepard, A., McMillan, T., \& Tate, G. (1998). Coming to class: Pedagogy and the social class of teachers. Boynton/Cook.

Tokarczyk, M., Fay, E. (1993). Working-class women in the academy: Laborers in the knowledge factory. University of Massachusetts Press.

Van Galen, J., \& Dempsey, V. (2009). Trajectories: The educational and social mobility of education scholars from poor and working class backgrounds. Sense.

Welsch, K. (2005). Those winter Sundays: Female academics and their working-class parents. University Press of America. 


\section{Table 2}

Altmetric Weights for Sources of Book Mentions

\begin{tabular}{ll}
\hline News & 8 \\
Blogs & 5 \\
Twitter & 1 \\
Facebook & 0.25 \\
Sina Weibo & 1 \\
Wikipedia & 3 \\
Policy Documents (per source) & 3 \\
Q\&A & 0.25 \\
F1000/Publons/Pubpeer & 1 \\
YouTube & 0.25 \\
Reddit/Pinterest & 0.25 \\
LinkedIn & 0.5 \\
Open Syllabus & 1 \\
Google+ & 1 \\
Patents & 3 \\
\hline
\end{tabular}

Source: How is the Altmetric Attention Score calculated? (n.d.). Retrieved from https://help.altmetric.com/support/solutions/articles/6000060969-how-is-the-altmetric-scorecalculated- 


\section{Table 3}

Research Impact and Instructional Impact for Books in the Study

\begin{tabular}{|c|c|c|c|c|c|c|}
\hline & $\begin{array}{l}\text { Altmetric } \\
\text { Score }\end{array}$ & $\begin{array}{l}\text { Total } \\
\text { Mentions }\end{array}$ & $\begin{array}{l}\text { Altmetric } \\
\text { Timeline }\end{array}$ & $\begin{array}{l}\text { Syllabus } \\
\text { Appearances }\end{array}$ & $\begin{array}{l}\text { Teaching } \\
\text { Score }\end{array}$ & $\begin{array}{l}\text { Google } \\
\text { Scholar } \\
\text { Citations }\end{array}$ \\
\hline $\begin{array}{l}\text { Adair \& Dahlberg } \\
\text { (2003) }\end{array}$ & 0 & 0 & --- & 18 & 1 & 89 \\
\hline Dews \& Law (1993) & 20 & 10 & $2015-2020$ & 31 & 2 & 352 \\
\hline Hurst \& Nenga (2016) & 1 & 1 & 2016 & 1 & 1 & 17 \\
\hline $\begin{array}{l}\text { Muzzatti \& Samarco } \\
\text { (2006) }\end{array}$ & 1 & 1 & 2018 & 5 & 1 & 71 \\
\hline $\begin{array}{l}\text { Oldfield \& Johnson } \\
\text { (2008) }\end{array}$ & 0 & 0 & --- & 9 & 1 & 39 \\
\hline Rosen (2013) & 0 & 0 & --- & 9 & 1 & 2 \\
\hline $\begin{array}{l}\text { Ryan \& Sackrey } \\
(1984 / 1996)\end{array}$ & 9 & 1 & 2016 & 11 & 1 & 452 \\
\hline $\begin{array}{l}\text { Shepard, McMillan, } \\
\text { Tate (1998) }\end{array}$ & 0 & 0 & --- & 12 & 1 & 64 \\
\hline $\begin{array}{l}\text { Tokarczyk \& Fay } \\
\text { (1993) }\end{array}$ & 0 & 0 & --- & 25 & 2 & 352 \\
\hline $\begin{array}{l}\text { Van Galen \& Dempsey } \\
\text { (2009) }\end{array}$ & 0 & 0 & --- & 2 & 1 & 17 \\
\hline Welsch (2005) & 0 & 0 & --- & 1 & 1 & 55 \\
\hline
\end{tabular}

(Data retrieved March 3, 2021) 